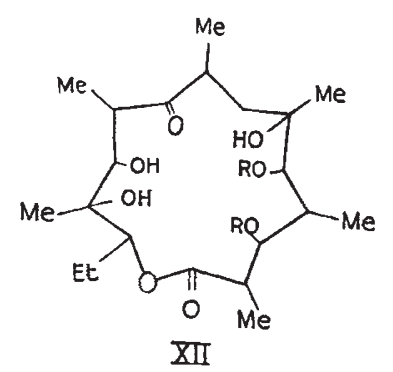

graphers (Sir Alexander Todd, Dorothy Crowfoot Hodgkin and co-workers); in addition to the magnitude of the molecule, the presence of a porphyrintype nueleus containing two directly linked, partly hydrogenated pyrrole rings is unique.

In the third of the Congress sections, major synthetical methods developed in recent years were given due prominence. K. Alder reviewed advances in our knowledge of the factors controlling the occurrence and direction of diene addition, knowledge which chemists owe in large measure to the work of his school. Organometallic compounds, which seem capable of unlimited development as synthetical reagents, were represented by a particularly interesting lecture by $\mathbf{K}$. Ziegler, who described his recent work on the polymerization of olefins by aluminium alkyls. This has resulted in a new process for the manufacture of polyethylene which promises to be of great technical importance; another application involves a replacement reaction yielding the anti-knock agent, lead tetraethyl, together with aluminium metal of high purity. The impact of fundamental research on quite a different field of applied chemistry, that of photographic sensitizers, was outlined by L. G. S. Brooker. The spectral properties of cyanine dyes, the most effective sensitizing agents known, are highly dependent on solvent or other physical environment, and it is now well established that the sensitizing curve is closely related to the light absorption curve of the dye-silver halide complex.

Although the dominant note of the Congress was on the pure rather than the applied side of chemistry, it thus provided many forcible reminders that civil. ization does not depend solely on the supply of power, an aspect which features so prominently in public discussion at the present time, but also on the harnessing of energy to the production of food, clothes, fuel and an infinite variety of other things. No one attending the Congress could have been left in doubt that organic chemistry is an immensely alive subject, and that we are only at the beginning of an era in which this branch of science will wield an ever-increasing influence on our daily lives, by substituting synthetic materials for natural products and by bringing under control biological processes which have so long sustained mankind unbridled.

Whether fired by such far-reaching thoughts, engrossed in new ideas or fresh problems, or merely stimulated by personal contact with many colleagues, members of the Congress dispersed in an elated mood, and a large proportion appeared to make for other parts of Switzerland to follow up a period of mental by another of physical recreation. The interesting encounters the writer had during a fortnight's climbing in the Grisons area certainly left him with the impression that seldom can so many organic chemists have been concentrated on so high a level.

It was announced that the next International Congress of Chemistry, covering all branches of the subject, will be held in Paris in July 1957, following the centenary celebration of the Société Chimique de France.
E. A. Braude

\title{
DUST AND HEALTH IN INDUSTRY
}

A DISCUSSION on "Dust and Health in Industry" was held by Section I (Physiology) of the British Association on the morning of September 1 at Bristol. It was opened by Dr. B. M. Wright (Medical Research Council Pneumoconiosis Research Unit), who dealt with the problem of measuring dust exposure in relation to pneumoconiosis of various types. Dr. Wright pointed out that, to understand the problem, it is necessary to consider some of the physical properties of dust and some aspects of the physiological behaviour of the respiratory tract. Airborne dust consists of particles of such small size that their rate of settling in air is very low, of the order of $5 \mathrm{~cm} . / \mathrm{min}$. for a particle $5 \mu$ in diameter, down to rates so low as to be negligible for particles less than about $1 \mu$. As a consequence, the size range of airborne dust particles depends upon the atmospheric conditions; in still air they will be very fine, whereas in a well-ventilated place relatively coarse particles will remain in suspension. Particles that are large enough to be visible are of little hygienic importance, so that it is not possible to judge the likely danger to health of an environment by visual inspection, and the use of an instrument is essential.

Turning to the physiological properties of the respiratory tract, Dr. Wright pointed out that it consists essentially of two parts-the upper respiratory tract, which is covered with ciliated epithelium, and the respiratory bronchioles and alveoli, which are not. Particles that settle on the ciliated epithelium will be removed within a matter of minutes or hours, whereas particles that penetrate to the alveoli may be retained indefinitely in the lung. The low settlingrate of very fine particles enables them to penetrate deeply into the respiratory tract, and the finer they are the farther they penetrate. The main mechanism by which they are trapped in the tract is sedimentation in the smaller bronchioles, although some loss of larger particles by impingement takes place in the nasopharynx and larger bronchi. The velocity of the air in the respiratory tract decreases continuously as it approaches the alveoli, where air movement is almost negligible, so that a substantial proportion of particles penetrating into the alveoli settle out and are retained. The proportion of particles retained is not much affected by the rate of breathing, because, although the increased air velocity tends to reduce the proportion of particles captured by sedimentation, impingement becomes a more important mechanism, and also the volume of air entering the alveoli is increased. It is important to realize that the penetration of particles to the alveoli has nothing 
directly to do with the relative dimensions of the air vessels and the particles, since the former are never less than $200 \mu$ in diameter, whereas the largest particle ever likely to penetrate to the alveolus is only about $5 \mu$ in diameter. Particles deposited in the alveoli are removed therefrom by phagocytes and are mostly deposited in the interstitial tissue, though some probably are also carried on to the ciliated epithelium and so removed from the lungs. Particles retained in the lungs, if they are relatively insoluble, will accumulate and cause pneumoconiosis. Particles deposited on the ciliated epithelium will cause no trouble unless they are soluble and irritating. Severely poisonous substances can cause general intoxication, whereas mildly irritating materials can cause chronic conditions such as byssinosis.

Owing to the wide range of particle sizes found in airborne dust, the range to be selected for sampling must be decided by the nature of the disease under consideration. If it is thought to be mainly due to irritation of the upper respiratory tract, particles up to 10 or $15 \mu$ diameter must be considered, whereas with a true pneumoconiosis only those less than $5 \mu$ are of importance.

Two main methods of assessing the quantity of dust are available-weighing and counting. The disadvantage of the former method is that it greatly overestimates the importance of large particles outside the respirable range, whereas the latter method is liable to be indeterminate, since the number of particles counted depends largely on the efficiency of the microscope used. In theory, a measurement of the surface area of dust might be of value, but practically it is difficult to obtain a measure of the true surface, and it is still necessary to confine the measurement to particles in the respirable size range. When collecting samples for microscope counting, care has to be taken that they are not distorted by the sampling instrument, so that the actual size of the airborne particles or aggregates can be judged. Methods are now available for collecting samples for gravimetric analysis, in which the larger particles are separated while sampling by a mechanism similar to that in operation in the respiratory tract.

Prof. J. Gough and Dr. A. G. Heppleston (Department of Pathology, Welsh National School of Medicine, Cardiff) then presented a paper on "The Harmful Effects of Pneumoconiosis", with particular reference to coal-workers. In the past, a high phthisis death-rate was associated with the inhalation of highly siliceous dusts, but a low rate with exposure to coal dust. Recent evidence, however, indicates that coal-mining is not such a healthy occupation as had been supposed and that tuberculosis plays an important part in the pneumoconiosis of coal-workers. Two forms of this disease may be distinguished. Simple pneumoconiosis is characterized by numerous discrete dust foci throughout the lung and represents the effect of dust alone. Complicated pneumoconiosis is often superimposed on the simple form, appearing as one or more densely fibrous black masses, and is considered to represent the combined effect of dust and tuberculosis. James has found bacteriological or histological evidence of tuberculosis in 40 per cent of these massive lesions from 245 men. When split into age-groups, however, 88 per cent of massive lesions from men less than forty showed tuberculosis, but only 29 per cent of lesions from men of sixty and more. These findings are interpreted as pointing to the tuberculous origin of massive fibrosis and suggest that, with increasing age, the infection dies out. A tuberculous element therefore exists in the massive fibrosis of coal-workers just as in classical silicosis, but in coal-workers it is largely concealed, except in the younger men. In 1,000 consecutive autopsy cases, there were 454 with massive fibrosis and, of these, 87 died from pulmonary tuberculosis but 218 from pulmonary heart disease due to vascular obliteration and emphysema caused by massive fibrosis. It can therefore be said that indirectly tuberculosis contributes greatly to the morbidity and mortality of coal-workers.

Simple pneumoconiosis, however, is very rarely fatal but can contribute to disability in men over the age of fifty. To establish the effect of simple pneumoconiosis on coal-workers, the pathological findings in the 1,000 autopsy cases were correlated with the disability during life. 29 cases were found in which dyspncea could be attributed only to simple pneumoconiosis, that is, after eliminating all other possible causes for dyspnce. This figure, however, underestimated the contribution of simple pneumoconiosis to disability because, to prove its effect, the 454 coal-workers with massive fibrosis had to be excluded and many of these had the more severe grades of simple pneumoconiosis. Free silica is not regarded as necessary for the development of the simple dust lesion of coal-workers, which bears no pathological resemblance to the classical silicotic nodule. A woman exposed for five years to the inhalation of carbon black, a very highly purified form of carbon, developed lung lesions identical with those of simple pneumoconiosis in coal-workers, thus supporting the conclusion that the reaction to airborne coal dust is non-specific. The development of the simple dust lesion in men exposed to a dust, such as coal or hæmatite, containing little free silica, therefore depends on mechanical accumulation of sufficient dust irrespective of its nature. (The precise structure of the simple dust lesion of coal-workers was then demonstrated by means of a film prepared from serial sections.) This lesion is in effect a fairly wide cylinder of vesicular tissue consolidated by dust and a little fibrous tissue, disposed around respiratory bronchioles, which are often dilated to produce the change known as focal emphysema. The mechanics of focal emphysema are interpreted on the basis of imbalance between the forces of inspiration and expiration, in which atrophy of bronchiolar smooth muscle appears to be the main factor. Dyspncea due to simple pneumoconiosis in coal-workers can therefore be attributed to rigidity of important segments of the bronchiolar tree and to the development of focal emphysema, which may be regarded as increasing the dead space of the lung, an effect likely to be greater as the emphysema becomes more severe.

Reference was also made by Prof. Gough and Dr. Heppleston to the pathological features of the recently recognized 'rheumatoid' nodules in the lungs of coalworkers with rheumatoid arthritis. These nodules have to be distinguished from foci of complicated pneumoconiosis. It was suggested that coal-workers with rheumatoid arthritis react abnormally to the collagen produced in infective pneumoconiosis, and the non-specific inflammatory reaction, which may occur in the absence of tubercle bacilli, is believed to be the 'rheumatoid' component of these peculiar nodules.

Mr. S. Smith (Factory Department, Ministry of Labour and National Service) dealt with protection against the risk of inhalation of industrial dust. Whereas the almost instinctive reaction to the 
existence of a dust hazard is to think of providing respirators, or local exhaust ventilation, these methods are wrong as first thoughts. The fundamental method, which has been used with success in many processes, such as bedding of pottery, grinding and 'sand-blasting', is to substitute a harmless dust for the dangerous one. Where this is not possible, the dangerous process ought to be totally enclosed: perhaps the most striking illustration of the success that can be achieved in this way is the control of radioactive dusts in the Atomic Energy Research Establishments. But complete enclosure, although often possible, is not always expedient. In such cases, as near total enclosure as is possible should be obtained, and suction applied to the inside of the cabinet, so that the enclosuro is sealed, as far as dust is concerned, by a dust-proof wall of moving air. To be effective, the air ought to be moving into the cabinet at about 150 linear feet per minute. This arrangement is none other than the common fume cupboard, which is to be found in every chemical laboratory; 'industrial' fume cupboards have been built around such plant as 'barrels' in foundries, asbestos blending benches, asbestos stock heaps, brass melting furnaces, and luminizing benches. Of course, most of the fume cupboards in industry are not the fragile glass structures commonly found in laboratories; those that enclose heavy plant have to be of steel, but the principle governing their use is the same. Obviously, very large machines can be protected in this way for very small running-costs.

When the degree of enclosure that can be achieved is small, very large air-flows are necessary to give even moderate control of the dust; this degenerate 'fume cupboard' is the familiar local exhaust hood. It is often unsatisfactory for such reasons as its high running-costs, the poor control of dust that it sometimes gives, and the fact that, if the machinery works at high speed, it is usually defeated; an example of this is the recent discovery by foundry research associations, in conjunction with the Factory Department of the Ministry of Labour and National Service, that the hood of the orthodox pedestal grinder (where good enclosure and high air flows are common) is ineffective because the dust moves under the influence of the wheel rather than of the air flow.

In the past, wetting has been relied upon to prevent the emission of dust. It has been found that this is successful only if gentle forces are at work, as in the stirring of a slurry ; with violent forces, as in grinding, or 'dunting' in the granite industry, wetting is not effective. Suppression of an existing dust cloud by sprays is very difficult and inefficient.

If none of these methods is completely effective, one is thrown on to the last resort-personal protection of each person at risk by the provision of respirators. The performance of dust respirators is governed by British Standard 2577, and many in use are unlikely to be able to pass its stringent tests.

Reliance is placed, sometimes, on the dilution of a dust cloud to a safe concentration by general ventilation. Experience has shown this to be quite wrong.

A protective suheme is usually built on the basis of samples having shown the existence of dangerous conditions; therefore, it is necessary to consider mothods of sampling. Research has shown that, for general purposes, only the thermal precipitator and absolute methods, such as sedimentation, are reliable. Even with these, statistical sampling errors occur; and others appear in the evaluation of the sample, in the form of counting errors, and errors due to having to allot a given particle to one of a finite number of size groups, instead of being able to give the size distribution in a sample as a continuous function. Therefore, to express results to three, and sometimes four, significant figures, as is common in the literature, is patently absurd; and the existing tables of 'maximum allowable concentrations' (which give results to three significant figures) are of little value. All workers in this field work to two numerical values for each material, whether they realize it or not ; the lower is the upper limit of concentrations that they know to be safe, and the upper is the lower limit of those that they know to be dangerous. The gap between the two limits is always wide, because there is a lack of fundamental information about which parameters make a given dust dangerous, and about the finer details of the mechanism whereby the dust causes its damage to the lung. The gap can become narrower as more fundamental information is discovered.

Dr. R. S. F. Schilling (Department of Occupational Health, University of Manchester) described the results of a recent investigation of byssinosis among Lancashire cotton workers. He gave a brief review of cotton processes and described the signs and symptoms of the disease. There were no specific X-ray changes in the lung fields, and diagnosis depended on the typical history of breathlessness and chest tightness on the first working-day of the week. Because of the lack of specific signs, the existence of byssinosis as an industrial disease has been doubted. Another masking feature is the high incidence of chronic respiratory disease in the general population. of the cotton towns of Lancashire. However, by using a modified Gaensler apparatus to measure the volume of air expelled during the first 0.75 sec. of a forced expiration, the 'maximum voluntary ventilation' was calculated and gave an indication of the degree of disability caused by byssinosis. A survey made in the Oldham area against controls from two engineering factories disclosed that 60 per cent of all persons at risk were suffering from the disease. In the worst cases, the maximum voluntary ventilation was only 60 litres/min., whereas that for controls of the same age was more than 100 litres $/ \mathrm{min}$. Out of 190 men between forty and sixty years of age working in card and blow rooms, some 26 were seriously disabled by byssinosis. The disease principally occurred in card rooms, and its prevalence was inversely related to the distance of the workers from the carding engines. Byssinosis presents a number of problems. Is it due to a specific allergen? What is the origin of the causative agent? Is it in the cotton, or the trash, or in the concomitant moulds or bacteria? No maximum allowable concentration of cotton dust is known, or has been suggested.

Dr. C. L. Sutherland reviewed the position from the point of view of national insuranco in Britain. He remarked that simple pneumoconiosis among conl miners is quite unimportant; and that statistics show that miners' wives suffer from heart disease almost to the same extent as their husbands. In reply, Dr. Heppleston emphasized that the clinicepathological correlation indicates that simple pnen. moconiosis can cause disability, but the figures give no indication of frequency. Furthermore, the occur rence among miners' wives of a high mortality from heart disease and pulmonary tuberculosis does not adversely affect the arguments relating to the nature of dust disease in the coal-workers themselves. 
Dr. B. Klinge queried the apparently different descriptions of the mechanism of deposition of dust in the lung as given by the different speakers, and wondered why Dr. Schilling had suggested no mechanism to explain how cotton dust attacked the lung. He regretted that Mr. Smith had limited the scope of his discourse to factories, since the principles he enunciated were plainly relevant to other dust problems, such as atmospheric pollution. Dr. Wright and Dr. Heppleston explained that the difference between the mechanisms they had described was only apparent, and was due to the fact that the latter had dealt with phenomena in the depths of the lung, whereas the former had not so limited himself. Dr. Schilling said that he had not given the explanation requested, because none is known. Mr. Smith replied that the subject of dust is so vast that he had had to limit his examples to those of which he had had substantial first-hand experience.

Mr. B. W. A. Crutchlow remarked that the slide of a carding engine showed an obsolete exhaust. Dr. Schilling agreed and said this showed the dusty nature of the work, but a much improved exhaust has been developed by the Shirley Institute, which, with the Factory Department, is paying particular attention to methods of dust control in card rooms.

\section{UTILIZATION AND EVALUATION OF GRASSLAND}

$\mathrm{T}$ HE first session of Section M (Agriculture) at the meeting in Bristol of the British Association was devoted to a discussion of the utilization and evaluation of grassland. The session was opened by Mr. R. A. Hamilton, who said that increases in world population will call for increased output by agriculture. As standards of living improve, there is a tendency for people to eat less tillage crops and more meat and dairy products. This will put an everincreasing strain on the supply of basic food nutrients, because the efficiency of conversion of plant foods to animal products is low. With about two-thirds of the agricultural land of the world under grass, it is vital that there should be efficient utilization, especially as grass that is well managed can produce greater yields of nutrients for livestock than almost any other crop and the cost of grass nutrients is low. The energy of grass has been estimated to cost, under recent British conditions, £11-14 per ton of utilized starch-equivalent, or $£ 17$ when preserved as silage and $£ 20$ as hay. By the same estimate, grazed kale costs $£ 17$, oats $£ 28$, artificially dried grass $£ 40$, and dairy cubes $£ 54$ per ton of starch-equivalent.

Where a variety of stock is consuming the grass and where other foods are sometimes given, it is difficult to measure the output of the grassland. The food requirements of the stock may, however, be estimated on the basis of their size and production together with the value of any other foods, and the contribution of the grass may then be determined by difference. This method has many shortcomings, but for comparative purposes is one of the most useful at present available, and by its means a working party of the Organization for European Economic Co-operation recently estimated that the yield of starch-equivalent per acre from grassland in various European countries was: Netherlands, $26 \cdot 2$ cwt. ; Denmark, $22 \cdot 3$ cwt. ; Belgium, $20 \cdot 0$ cwt. ; Norway, $19 \cdot 0$ cwt. ; West Germany, $17 \cdot 2$ cwt. ; Great Britain, $16.7 \mathrm{cwt}$; and France, $11.1 \mathrm{cwt}$. The low value for Great Britain may be partly due to an overestimate of the value of the large amounts of concentrates used. Surveys show that, with good management, yields of 30 or even 40 cwt. can be obtained in Britain; few arable crops will produce values of this order. It has, however, been estimated that even in New Zealand, with its ideal climate and highly specialized grassland dairy industry, utilization of grassland is still only 50 per cent of the potential.

Maximum utilization will be achieved with a careful system of management which includes the longest possible grazing season and an efficient system of storing all grass produced in excess of immediate requirements. This was illustrated diagrammatically by $\mathrm{Mr}$. Hamilton from the management followed in fat-lamb production in New Zealand. By this system, $400-600 \mathrm{lb}$. of meat is produced annually per acre. In New Zealand the fit between production and the requirements of dairy cattle is less close than for fat lambs, but grass in some form nevertheless provides for the full needs of most dairy herds. In consequence, New Zealand can provide lamb and butter at lower costs than any other country in the world.

In Britain the liquid milk market requires a more even spread of milk production through the year, yet the grazing season is considerably shorter than in Now Zealand. Mr. Hamilton accordingly stressed the need to lengthen the grazing season and to secure efficient grass storage for winter feeding. Methods of grass conservation are, therefore, of very great importance in the British economy. With any of the recognized methods there will be losses of nutrients, and it has been estimated that average losses of starch-equivalent are of the following order : artificially dried grass, 5 per cent; silage, 22-35 per cent; hay, 40-45 per cent. These all depend somewhat on the method employed and the efficiency with which it is applied; clearly at times the losses may be much higher. At present, hay and silage account for more than 95 per cent of all grass conserved in Britain and, of this fraction, 90 per cent is still in the form of hay. Silage-making is more suited to the British climate than hay-making, and Mr. Hamilton was of the opinion that we should be making 15 million tons of silage instead of the $2 \frac{1}{2}$ million tons being made at present.

Before a completely efficient system of grassland utilization can be achieved, Mr. Hamilton concluded, there are many problems that have to be overcome. Perhaps among the most important of these are the increased incidence of hypomagnesæmia, bloat, infertility, various allergies and parasitism that has followed more intensive methods. Unless these problems are solved, it will not be possible for grass to play its potentially important part in lowering the cost of production of ruminant products.

The question, raised by Mr. Hamilton, of the difficulty of measurement of the output of pastures has recently received considerable attention. Three types of approach have now been tried, each with some success; they are based either on a measurement of the amount of grass removed from the field, the amount consumed by the cow, or of the production of the cow. Mr. C. Line (National Institute for 